is characteristic of religious orders to seek obedience without scepticism, but it spells the death of intellectual inquiry. All variants of 'because I say so', or because the Koran says so, or the Bible says so, or the Upinashads say so, or Freud says so, or Marx says so, are simply different means of stifling intellectual dissent."

This is the voice of a disillusioned apostate, about whom several questions remain unanswered. The significance of his story, however, resides more in what it reveals of his former creed than in what it reveals of the author himself. $\mathrm{He}$ has provided a striking and wellpublicized illustration of Ernest Gellner's dissection of the psychoanalytical movement as a highly organized secular faith, a complex belief system applying a scientific idiom to a variety of social and personal needs. But those needs will not be dispelled by reason and logic. Pierre Janet's history of psychological healing (Psychological Healing, Volumes 1 and 2 (translated by E. and C. Paul), Allen

\section{In for a penny, in for a pound}

\section{Norman Myers}

Linking the Natural Environment and the Economy. Edited by C. Folke and T. Kaberger. Kluwer: 1991. Pp. 305. Dfl. $150, \$ 100, £ 52$.

Values for the Environment. By J. T. Winpenny. HMSO: 1991. Pp. 277. £14.95.

ENVIRONMENTALISTS have much to learn from economists. For instance, can a natural resource such as a species really be 'beyond value', as many conservationists claim? Americans gladly pay $\$ 15$ million to save the California condor, but they might well jib at $\$ 15$ billion. Similarly, that key tool of economics, marginal analysis, has much to say about value where it most counts, namely at the margin: we would presumably pay more to save the tenth last panda than the thousandth last.

Conversely, economists have much to learn from environmentalists. Economics has little to say about the long-term future; a discount rate of 10 per cent effectively proclaims there is no future beyond seven years. Yet some of today's environmental assaults will leave their effects for centuries and millennia - in the case of mass extinction of species, for millions of years. Moreover, many economists assume that the welfare of future generations will continue to be better than that of the previous generation, so we should not worry unduly about the problems we may be passing and Unwin, 1925) demonstrates clearly that such denunciations may serve to modify, but will not eradicate, the responses to the continous and widespread call for hope, support and consolation on the part of numerous people who are ready and willing to believe in what is offered for the purpose. Stripped of its scientific pretensions, psychoanalysis is merely an elaborate example of the many forms of psychotherapeutic activity that arise in response to these demands. The counsellors, the scientologists, the cultists of various persuasions and some 'alternative' medical practitioners all testify to this phenomenon. As medicine attempts to shake off the trappings of magic and theology it is having to accept the old adage that while the physician's scepticism may be the best means of attaining truth, the patient's faith is often needed to attain health.

Michael Shepherd is at the Institute of Psychiatry, De Crespigny Park, Denmark Hill, London SE5 8AF, UK.

on: our descendants will find a way to sort them out, just as their forebears have always done. This thesis no longer holds when present-day environmental degradation looks set to deplete the world of many of its crucial natural resources. Most importantly, economics is largely based on an incrementalist approach to analysis, where situations change little by little rather than by big jumps. But ecosystems often undergo large shifts in make-up and dynamics, as is likely to be the case today as humans irreversibly transform the planetary ecosystem itself.

In short, it seems that economists and environmentalists do not talk enough to each other. They have been urged to compare notes for decades, and on all kinds of cogent grounds. But in my experience, the gulf of misconception is greater than ever.

All the more welcome, then, are these two books, each of which tries to bridge the gap. Linking the Natural Environment and the Economy, edited by two Swedish aficionados of the fields, is the more erudite and professional, dealing with "the dependence of socioeconomic systems on healthy environments and functional ecosystems". It seeks to demonstrate that "it is no longer possible to take environmental goods and services for granted". Instead they must be methodically taken into account by decision-makers at all levels. The book does a sound job, with much fine-grain analysis, while eschewing econometric minutiae.

The first part delineates several types of ecological and economic linkages, assessing their scope and importance through factors such as institutions, en- vironmental effects and energy flows. The second part presents empirical analyses of the part played by environmental resources in economics, and contains examples from landscape change, agriculture, wetlands, and coastal and marine systems. Useful measurements such as plant growth, industrial energy, cropland nutrients, grain yields, soil erosion, eutrophication of water bodies and outputs of fisheries are invoked throughout, and there is a preliminary evaluation of trade-offs between competitive forms of land use. The third part looks at human impacts on environments in developing countries, through assessment of, for example, pesticidal pollution in Kenya and conservation in Central America.

The final chapter provides an overview of the eight case studies and their findings. This is the most illuminating chapter because it attempts, with some success, to define operationally the key concept of environmental economics, sustainable development.

By contrast, Winpenny adopts a sternly pragmatic approach. The author is a development economist with extensive field experience, and he hopes that his book will be "of operational value in project appraisal and, ultimately, policy formulation"; his intended reader is "an economist working with project responsibilities". He quickly plunges into a summary consideration of important habitats (such as watersheds and rainforests, as well as urban and industrial ones), and follows this with a review of evaluation techniques including costbenefit analysis and "environmental benefit estimators". In the second half of the book he deals with practical applications of economics to, for example, desertification, loss of biodiversity, pollution and climate change, and includes sections on project appraisal and policy adjustment. All this is supported by many examples and small case studies.

The book is a fine analytical aid for project managers. But Winpenny seems to accept the situation 'outside the window' as given, with virtually no critical assessment of whether we are right $a b$ out general environmental trends, or of what environmental economics as a discipline can offer if we decide we are not.

Both books can be commended to those trying to straddle the unfortunate divide between economics and environment; they are especially timely in the light of the United Nations Conference on Environment and Development to be held in June 1992, where interdisciplinary and intersectorial linkages will be central to the deliberations of the world's nations.

Norman Myers is a consultant in environment and development at Upper Meadow, Old Road, Headington, Oxford OX3 8SZ, UK. 